\title{
Influence of microwave irradiation on lipase-catalyzed kinetic resolution of $( \pm)$-mandelonitrile
}

\author{
Sandra S. Ribeiro, Julieta R. de Oliveira, André L. M. Porto*
}

Instituto de Química de São Carlos, Universidade de São Paulo, Av. Trabalhador São-carlense, 400, 3560-970, São Carlos, SP, Brazil, *sandrinhasr@iqsc.usp.br

Keywords: Enzymatic kinetic resolution, Candida antarctica, Mandelonitrile, Microwave Irradiation

\section{INTRODUCTION}

The synthesis of optically pure cyanohydrins is an area of growing interest in synthetic chemistry ${ }^{1}$. Microwave irradiation has also attracted considerable interest in recent years because of their advantages, such as reduced chemical reaction time, reduced side reactions, increased yields and improved reproducibility ${ }^{2}$. The objective of this study was investigate the kinetic resolution of $( \pm)$ mandelonitrile (1) using lipase from Candida antarctica under microwave irradiation and conventional conditions.

\section{RESULTS AND DISCUSSION}

The kinetic resolution of $( \pm)$-mandelonitrile 1 was made with the lipase of Candida antarctica $(160 \mathrm{mg})$ using (80 $\mu \mathrm{L}, 0.067 \mathrm{mmol})$ of rac-mandelonitrile in toluene $(10 \mathrm{~mL})$ and vinyl acetate $(500 \mu \mathrm{L})$ under microwave irradiation and conventional heating. Microwave irradiation experiment was performed with Discover System from CEM Corporation: The whole reaction mixture was placed in the microwave oven and irradiated at $80^{\circ} \mathrm{C}$, about $200 \mathrm{~W}$. The reaction progress was monitored by collecting samples $(2 \mu \mathrm{L})$ according to the time indicated in Table 1, which were analyzed by GC-FID with chiral stationary phase, while conventional heating lipasecatalyzed acylation reaction was made in an orbital shaker at $32^{\circ} \mathrm{C}$ and $130 \mathrm{rpm}$. The results are summarized in Table 1.

The microwave irradiation showed to be efficient for the enzymatic resolution providing decrease in reaction time and good yield and enantiomeric excess. In addition, the conventional kinetic resolution was performed in 7 days producing $(S)$ mandelonitrila 2 (Table 1). The (R)-mandelonitrile (1) unreacted, by conventional and microwave reactions, resulted spontaneously in a chemical equilibrium producing the benzaldehyde (Scheme 1).

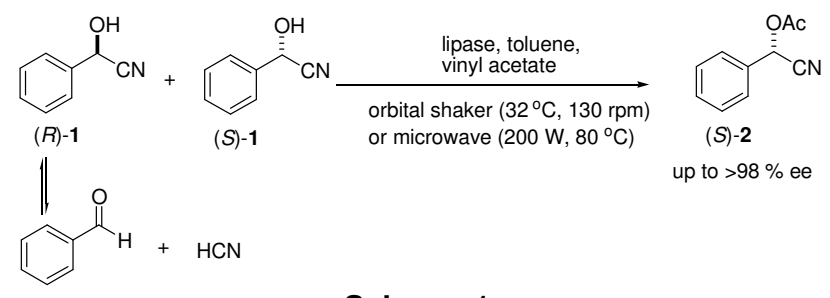

Scheme 1.

Table 1. Comparison of microwave irradiation and convencional heating on lipase kinetic resolution of $( \pm)$-mandelonitrile (1).

\begin{tabular}{|c|c|c|c|}
\hline Time (h) & $c(\%) \mathbf{1}$ & $c(\%) \mathbf{2}$ & $e e(\%) \mathbf{2}$ \\
\hline \multicolumn{4}{|c|}{ Microwave Irradiation } \\
\hline 2 & 75 & 25 & $>98$ \\
\hline 4 & 68 & 32 & $>98$ \\
\hline 6 & 63 & 38 & $>98$ \\
\hline 8 & 60 & 40 & $>98$ \\
\hline \multicolumn{4}{|c|}{ Conventional Experiment } \\
\hline 48 & 67 & 33 & $>98$ \\
\hline 72 & 65 & 35 & $>98$ \\
\hline 120 & 63 & 37 & $>98$ \\
\hline 168 & 54 & 46 & $>98$ \\
\hline
\end{tabular}

CONCLUSION

This study shows the first efficient kinetic resolution of ( \pm )-mandelonitrile (1) by lipase from $C$. antarctica under conventional and microwave conditions, producing exclusively the (S)-mandelonitrile acetate (2) in high selectivity (> 98\% ee). The kinetic resolution in toluene proceeded with rate enhancement reducing chemical reaction time in microwave irradiation in comparison with conventional experiment.

\section{ACKNOWLEDGEMENTS}

ALMP gratefully acknowledges CNPq and FAPESP for their financial support. SSR and JRO thank FAPESP for scholarships The Novo Nordisk for donating the CALB enzyme (Novozym $435^{\circledR}$ ).

\section{REFERENCES}

${ }^{1}$ Xiong, J.; Wu, J.; Gang, X.; Yang, L. Chem. Eng. J. 2008, 138, 258.

${ }^{2}$ Bachu, P., Gibson, J. S.; Sperry, J.; Brimble, M. A. Tetrahedron: Asymmetry 2007, 18, 1618. 